\title{
Multidisciplinary attitudes to people with dementia; training and environmental factors play a role in caring for people with dementia in a Cardiac Catheterisation Laboratory
}

DOI:

10.1108/QAOA-10-2015-0050

\section{Document Version}

Accepted author manuscript

Link to publication record in Manchester Research Explorer

\section{Citation for published version (APA):}

Ainsworth, K., \& Richardson, C. (2017). Multidisciplinary attitudes to people with dementia; training and environmental factors play a role in caring for people with dementia in a Cardiac Catheterisation Laboratory. Quality in Ageing and Older Adults, 18(4), 235. https://doi.org/10.1108/QAOA-10-2015-0050

\section{Published in:}

Quality in Ageing and Older Adults

\section{Citing this paper}

Please note that where the full-text provided on Manchester Research Explorer is the Author Accepted Manuscript or Proof version this may differ from the final Published version. If citing, it is advised that you check and use the publisher's definitive version.

\section{General rights}

Copyright and moral rights for the publications made accessible in the Research Explorer are retained by the authors and/or other copyright owners and it is a condition of accessing publications that users recognise and abide by the legal requirements associated with these rights.

\section{Takedown policy}

If you believe that this document breaches copyright please refer to the University of Manchester's Takedown Procedures [http://man.ac.uk/04Y6Bo] or contact uml.scholarlycommunications@manchester.ac.uk providing relevant details, so we can investigate your claim.

\section{OPEN ACCESS}


Multidisciplinary attitudes to people with dementia; training and environmental factors play a role in caring for people with dementia in a Cardiac Catheterisation Laboratory

\begin{tabular}{|r|l|}
\hline Journal: & Quality in Ageing and Older Adults \\
\hline Manuscript ID & QAOA-10-2015-0050.R4 \\
\hline Manuscript Type: & Research Paper \\
\hline Keywords: & $\begin{array}{l}\text { Acute, Attitudes, Cardiac Catheter Laboratory, Cognitive, Dementia, } \\
\text { Hospital, Multidisciplinary, Training }\end{array}$ \\
\hline \multicolumn{2}{|l}{} \\
\hline
\end{tabular}

SCHOLARONE ${ }^{\text {m }}$

Manuscripts 
Multidisciplinary attitudes to people with dementia; training and environmental factors play a role in caring for people with dementia in a Cardiac Catheterisation Laboratory

\begin{abstract}
Purpose - To explore multidisciplinary attitudes and environmental factors affecting dementia care in the Cardiac Catheter Laboratory.

Design/methodology/approach - Questionnaires $(n=87)$ were distributed in a hospital Cardiac Catheter Laboratory in the North of England. We utilised The Dementia Attitudes Scale which incorporates two subscales, Social Comfort and Dementia Knowledge. In addition, a newly devised questionnaire asking about perceptions of how the cardiac catheter laboratory environment affected care of patients with dementia was added.

Findings - The response rate was $71 \%(n=62)$. Years' experience in the cardiac catheter laboratory was associated with lower Social Comfort scores $(p=0.026)$. Dementia training was associated with higher mean Dementia Attitudes Scale and Social Comfort scores $(p=0.021: p=0.007)$. Participants who had undertaken 'Professional studies' had higher Dementia Attitudes Scale and Dementia Knowledge mean scores $(p=0.038$ : $p=0.046)$ but 'On-the-job' training was perceived as most beneficial $(32 \%, n=20)$. Unit co-ordinators, and nurses felt the cardiac catheter laboratory was an unfavourable environment for patients with dementia. Care was perceived to be impaired by environmental functionality, equipment and the presence of lonising radiation.
\end{abstract}

Research Limitations/Implications - The small sample limits generalisability. Although the Dementia Attitudes Scale is a validated questionnaire it has not been widely used so reliability of these results is unclear.

Practical Implications - Caring for patients with dementia has unique challenges especially in areas like the cardiac catheter laboratory. These results suggest that practical experience and training can affect the perception of staff to patients with dementia hence there may be a need to assess what would be the most appropriate training to give health professionals in the future.

Originality/value - We believe this to be the first multi-professional research study into care of patients with dementia in a specialised acute unit. This was the most diverse sample 
known to have attitudes to dementia measured quantitatively in an acute hospital department and the results need to be replicated before practice should be changed.

Keywords - Acute, Attitudes, Cardiac Catheter Laboratory, Cognitive, Dementia, Hospital, Multidisciplinary, Training.

Article Classification - Research paper

\section{Introduction}

Globally there are 47.5 million people living with dementia, with 7.7 million people newly diagnosed each year (World Health Organisation 2012a). In the UK there are 800,000 patients with dementia with a societal annual financial burden of $£ 23$ billion (GOV.UK, 2013: Alzheimer's Society, 2012). Numbers are expected to double by 2040 (GOV.UK, 2013) and it may be even higher if the current low diagnosis rates are improved (DOH, 2013).

Multi-morbidity is common among patients with dementia and includes hypertension, depression and coronary heart disease (Guthrie et al, 2012) which means that many patients with dementia may be admitted to hospital for conditions other than their dementia.

At any one time in the UK a quarter of patients in hospitals have dementia (DOH, 2013), with the majority admitted for physical problems including, falls, hip fractures, hip replacements and urinary conditions (Nightingale et al., 2001; Alzheimer's Society, 2009). With this in mind the World Health Organisation (2012b) identified the risk that patients with dementia may not get the specialised care they require when admitted into areas specialising in other conditions. There is a potential that due to inappropriate attitudes and/or lack of knowledge their rights may not be protected resulting in the potential for suboptimal care (World Health Organisation, 2012b). In the UK this prompted a $f 54$ million investment to improve staff attitudes, knowledge, experience and skills (DOH, 2009) to enable the development of dementia friendly hospitals (GOV.UK, 2013). In order to improve care of people with dementia the aim of dementia friendly hospitals is to use the criteria identified by the World Health Organisation (2012b) to improve outcomes and experiences by focusing on helping people with memory loss, disorientation, confusion, and agitation. 
Existing research into the care of patients with dementia in hospitals is largely qualitative with a strong focus upon ward environments and on nursing and tends to suggest that care is suboptimal. Baillie, Merritt and Cox (2012) examined student nurses experiences of dementia care in hospitals $(n=464)$. Using focus groups the students reported a lack of dementia knowledge and skills amongst staff on wards. The students felt this resulted in negative staff attitudes which were confounded by a lack of organisational support. These issues were corroborated by another focus group study (Fukuda et al., 2015) of 50 experienced nurses who also identified that nurses do their best to ameliorate the effects of environmental and institutional limitations but are not always successful. In an attempted multiprofessional semi-structured interview study $(n=25)$ exploring experiences of dementia care in acute hospitals, attitude alongside a lack of knowledge and skills were identified to affect the care of patients with dementia (Borbasi et al., 2006). The final sample however was predominantly nurses rather than a mix of professionals. Nolan (2006) explored nurses experiences $(n=7)$ of caring for older patients in an acute setting. Participants described how time constraints limited the nursing of patients with dementia in acute environments, and sometimes led to nurses taking over patient activities.

An ethnographic study of three wards utilised participant observation and interviews (Cowdell 2010). Participants were 25 registered nurses, 33 nursing assistants and 11 patients diagnosed with dementia and they reported attitudinal environmental and organisational problems when caring for patients with dementia. A lack of staff empathy was also noted. It is generally acknowledged that the physical environment of many hospital departments do not cater for the needs of patients with dementia (The Kings Fund 2013).

The World Health Organisation (World Health Organisation, 2012b) has recommended training as an answer to improving care for patients with dementia. Results so far however have not been convincing (Spencer et al., 2013). Using semi-structured interviews $(n=40)$, Spencer and colleagues (2013) compared family carers opinion of care in an area which had been adapted specifically to optimise care of patients with dementia with a general ward environment. Both settings were identified to have positive and negative aspects to 
dementia care, but the modified environment did receive a higher level of satisfaction and lower levels of dissatisfaction.

Much of the literature has not been able to achieve a multiprofessional perspective and in the UK the DOH $(2009$, p.13) describe an urgent need to research the care of patients with dementia from a multidisciplinary and multi-department perspective. This study aimed to do this by focusing on a cardiac catheter laboratory $(\mathrm{CCL})$ where numerous treatments for cardiac conditions are performed. Cardiac catheter laboratories have separate areas for undertaking procedures and for recovery, which means that patients move between the areas which may be manned by different groups of staff.

The majority of procedures performed in CCLs are performed whilst patients are awake. Cardiac catheter laboratories are technical and dominated by large equipment e.g. monitoring and X-ray screens, cardiac arrest trolleys and defibrillators and specific machinery to treat cardiac conditions. Central to this equipment is a narrow X-ray table and large X-ray camera. This bulky equipment moves during procedures, getting close to patient's chests to obtain quality images and reduce patient exposure to ionising radiation. Excessive exposure to ionising radiation is a known health risk. Therefore, staff working in such areas are provided with training and advice on how to reduce personal risk of exposure. The most simple of which is keep as far away from the source of ionising radiation as possible (the camera). This presents real challenges to staff as X-ray images are obtained in many cases by prolonged exposure times producing 'films' rather than still images. Staff are unable to approach the patient during these filming periods. Thus, accessibility to the patient is limited whilst procedures are in progress and a real challenge when caring for patients with dementia.

The CCL recruited in this study regularly admits patients with dementia for implantation of cardiac pacemakers and pacemaker generator box changes, treatment to relieve angina and emergency treatment of myocardial infarction.

\section{Method}


This was a cross-sectional survey using self-completed questionnaires. University ethical approval was granted (reference Ethics/4129).

\begin{abstract}
Aims
The primary aim was to measure the attitudes of a multidisciplinary CCL team to patients with dementia and to identify factors that affect those attitudes. Secondary aims explored challenges imposed by the environment and how these impacted on care from a staff perspective.
\end{abstract}

\title{
Sample
}

A purposive multidisciplinary $\operatorname{CCL}$ sample $(n=87$; consultants $n=14$, registrars $n=13$, radiographers $n=15$, cardiac physiologists $n=13$, nurses $n=23$, support staff $n=9$ ) were invited to participate from one large CCL within an NHS Hospital in the North of England. Inclusion criteria

- All professions.

- Contracted to work in the CCL.

\section{Exclusion criteria}

- CCL staff without direct patient contact.

- Students not employed by the department.

\section{Questionnaire}

The Dementia Attitudes Scale consists of twenty statements scored using seven point Likert scales (O'Connor and McFadden 2010). Ten statements measure cognitive attitudes (Social Comfort) and ten statements measure behavioural and affective attitudes (Dementia Knowledge). Six of the twenty statements are reverse scored to reduce acquiescence bias. Scores range from 20 to 140 . Higher scores indicate a more positive attitude to dementia. Example statements are; 'I am not very familiar with Alzheimer's disease and related dementias' and 'People with Alzheimer's and related dementias can enjoy life.' 
The Dementia Attitudes Scale scores well for reliability (Cronbach alpha $=0.83$; range 0.720.87 ) and its completion is thought not to be affected by social desirability (O'Connor and McFadden 2010). Permission for use was obtained from the authors.

Environmental effects of the $\mathrm{CCL}$ on patients with dementia were obtained from staff. Perceptions were measured using bespoke questions adapted from the 'Is your ward dementia friendly?' questionnaire devised by The Kings Fund (2013). Although originally designed to be adapted to different hospital environments many components were not pertinent to the $\mathrm{CCL}$ and were dropped. Twelve environmental questions/statements were utilised focusing upon the two main areas in the $\mathrm{CCL}$ (six for recovery and six for the laboratories). A four point Likert scale was applied to the statements to support statistical analysis. Maximum and minimum scores ranged from 12 to 48, higher scores indicated a more positive perception of the environment. Examples of questions are; 'How appropriate is the recovery area for people with Alzheimer's disease and related dementias? (Very inappropriate (1) to very appropriate (4))' and 'How does the equipment in the laboratories affect the quality of care given to people with Alzheimer's and related dementias? (Negatively (1) to Positively (4))'. Free text boxes were provided for participants to comment.

Participants' characteristics were recorded. An additional two statements (four point Likert scale) were included to explore participant's perception of the journey taken by patients with dementia through the $\mathrm{CCL}$ and the quality of care provided e.g. 'What is your perception of the journey taken by a person with Alzheimer's and related dementias through the Cardiac Catheter Laboratory?' and 'What do you think about the quality of care delivered to the person with Alzheimer's and related dementias by the multidisciplinary team in the Cardiac Catheter Laboratories?' In both cases the Likert scale range was 1 Poor to 4 Excellent.

\section{Data collection/analysis}

Email invitations containing a link to the online questionnaire were sent to all eligible members of staff. A sample size calculation was not performed as all eligible staff within the department was invited. The questionnaire was available for four weeks and email 
reminders were sent to everyone as it was not possible to trace respondents. Paper versions were available for those who preferred them. Completed paper questionnaires were posted into a secure box, which were opened and inputted onto the online version by independent audit staff.

The StatsDirect programme was used to analyse data following data cleansing. Means and standard deviations were reported on summed scores. Normal continuous distributions (including skew) were assessed using normal plots, histograms and the Shapiro-Wilk test. Unpaired t-tests and Levene's test was used prior to one-way 'analysis of variance' (ANOVA) in normally distributed data. Kruskal-Wallis tests and Mann-Whitney $U$ tests were used on data that was not normally distributed and where appropriate Tukey-Kramer tests were applied to multiple comparisons.

Number of years CCL experience was collected and analysed as categorical data. Receipt of training (Yes/No) was analysed to examine associations with summed Dementia Attitudes Scale, Social Comfort and Dementia Knowledge attitude scores. Frequency data also examined which disciplines had received dementia related training (medical staff; allied professionals; nursing; support staff). The type of training received was analysed to see if training type is associated with summed Dementia Attitudes Scale, Dementia Knowledge and Social Comfort scores. Categories were; short course/workshop, professional studies, on-the-job training and personal experience. Personal experience was included as this was considered a valid informal way to receive dementia 'training'.

The suitability of the environment for caring for patients with dementia was compared between professions, participant characteristics and role (specifically the co-ordinator role). Free text analysis explored staff opinions of the environment in more depth. This data was analysed by grouping the comments into subjects and then into themes.

\author{
Results \\ Sixty-two participants responded (response rate 71\%). See Table 1 for participant \\ characteristics.
}




\section{Experience}

The number of years' CCL experience, assessed as two groups $\leq 5(n=23,37.7 \%)$ and $\geq 6$ $(n=37,62.3 \%)$, showed no significant difference in Dementia Attitude scores $(t=1.96, d f=58$, $95 \% \mathrm{Cl}=-11.0$ to $0.1, \mathrm{p}=0.054)$. However, participants with $\leq 5$ years' experience had significantly lower mean Social Comfort scores than participants with $\geq 6$ years' experience $(t=2.29, d f=58, p=0.026,95 \% \mathrm{Cl}=-9.04$ to -0.61 : mean 46.4 versus 51.2$)$. Thus fewer years' work experience was associated with participants holding more negative ideas and beliefs of patients with dementia.

\section{Training}

Thirty-seven percent had received dementia training $(n=23)$. Registrars were the most likely discipline to have received training, whereas no cardiac physiologists had dementia training. A higher percentage of medical staff had received training on dementia (see Table 2).

Dementia Attitudes Scale and the subscale Social Comfort, mean scores were significantly higher in the group who had training (Dementia Attitudes Scale; $t=2.37, d f=59, p=0.021,95 \%$ $\mathrm{Cl}=-13.0$ to -1.1 : Social Comfort, $\mathrm{t}=2.82, \mathrm{df}=59, \mathrm{p}=0.007,95 \% \mathrm{Cl}=-10.0$ to -1.7$)$. Training was more likely to be in the form of a short course/workshop $(n=13,18 \%)$ with professional studies ( $n=11,16 \%)$ next prevalent, followed by on-the-job training $(n=10,14 \%)$.

On-the-job training was perceived as the most beneficial form of training $(32 \%, n=20)$, followed by personal experience $(27 \%, n=17)$. Short courses or workshops was perceived as most beneficial by $15 \%(n=9)$; while professional studies was thought to be beneficial by just $5 \%(n=3)$.

Tukey-Kramer multiple comparisons were undertaken to compare Dementia Attitudes Scale scores between the different forms of training. The results revealed that participants who had received dementia training during professional studies had higher Dementia Attitudes Scale scores than participants who received training in the form of short courses/workshops $(F=3.05, d f=3$ and $44, p=0.038)$. Similarly, Dementia Knowledge scores were significantly higher in the professional studies group than the short courses or workshops, on-the-job and personal experience groups $(T=8.01, d f=3, p=0.046)$. 


\section{Perceptions of the environment}

Coordinators were predominantly female $(79 \%)$ and nurses $(63 \%, n=10)$. Rank scores found non-coordinators perceived the recovery area more positively than coordinators $(U=574.5$, $p=0.005)$. Perceptions of the recovery area varied between disciplines $(F=2.56, d f=5$ and 54 , $p=0.038$ ). Nurses perceived the recovery area as less suitable for patients with dementia than consultants (mean difference $=4.0,95 \% \mathrm{Cl}=0.2$ to $7.8, \mathrm{p}=0.036$ ). Females viewed the recovery area and the laboratories more negatively than males $(t=2.35, d f=58, p=0.022,95 \%$ $\mathrm{Cl}=0.3$ to 3.9: $\mathrm{U}=587, \mathrm{p}=0.015)$. There was no difference in perception of the suitability of the laboratory between disciplines $(T=9.55, d f=5, p=0.089)$. However, nurses still had the lowest perception score, whilst consultants and cardiac physiologists had higher perception scores (respective mean scores: $11.7,15.1,14.9$ ).

\section{Perceptions of patient journey and care}

Staff regarded care provided to patients with dementia as good as $n=48(79 \%)$ chose 3 or 4 on a 4 point scale ( 4 being excellent care). Although $n=33(55 \%)$ showed concern over the adequacy of the patient journey within the CCL where patients are moved between different sectors/rooms due to the nature of the procedures undertaken (see Table 3).

\section{Free text analysis}

Participants described the recovery area as busy and unpredictable, filled with unfamiliar faces, noises and crowds. The emergency nature of some patient admissions also meant functionality and equipment reduced the dementia friendly nature of the recovery area. Participants felt this likely to increase anxiety for patients with dementia. It was widely considered that there were adaptations that could be made to the recovery area to make it more receptive for patients with dementia with the caveat that the area would always remain "strange" for patients with dementia:-

"...use of colour and defined spaces and objects should be easy to accommodate..." (P30)

"...by having set familiar faces treating the patient." (P34) 
In contrast, the laboratories were judged to be "very hard" to change due to the essential layout, equipment and functional nature of the area. These factors led to expressions of frustration about how well participants were able to care for patients with dementia:-

"...the realities of angiographic procedures mean there is a substantial gap between what the staff wants to do and what they physically can do." (P30)

"...There is a conflict between additional attention that might be needed and complying with radiation protection recommendations etc." (P1)

"There is blue flooring in the labs which is inappropriate but unable to be changed due to costing!! We could place visuals such as clocks with times and dates. Play music which is familiar to the patients." (P34)

Participants commented that clinical areas are designed to enable operators to perform their task:-

"The cardiac catheter lab is a very technical environment and the majority of patients do not have dementia. So the focus should be on appropriate nursing/medical care for these patients during their time in the cath labs rather than altering the environment." (P46)

Organisational difficulties also limited the ability to care, reassure and spend time with patients with dementia in both the recovery area and the laboratories; a balancing act was described and exacerbated when staffing levels were low. Participants didn't always feel supported to look after patients with dementia and suggested adapting working practices as a way to improve experiences for patients with dementia:-

"Greater care and personal attention should be possible for occasional patients within current staffing levels, but might require flexibility." (P1) 
In-spite of the unique challenges and frustrations described by participants there were many person-centred views in support of equal access and individualised care and an overall perception that participants delivered quality and compassionate care.

"Despite the challenges logistically of caring for patients in the cath lab, the staff at XXXX show the benefit of their experience and compassion in keeping their patients with cognitive impairment as comfortable as can be achieved." (P30)

"Staff try their very best to alleviate anxiety by talking to them and staying with patient at all possible times. (P15)

"all the staff are excellent with these patients." (P56)

\section{Discussion}

This study was the first to quantitatively measure attitudes to working with patients with dementia with participants' from CCL. Healthcare staff are widely regarded as holding negative attitudes towards patients with dementia (George et al., 2013: Baillie et al., 2012: World Health Organisation, 2012b: Borbasi et al., 2006). However, our results have shown largely positive attitudes of acute hospital staff to patients with dementia and agree with the results from another quantitative study by Nilsson et al., (2012). As in this study Nilsson et al., (2012) aimed to measure attitudes of multidisciplinary staff. However, their sample included mainly nurses and only $4 \%$ allied professionals and $7 \%$ doctors, which prevented them from differentiating attitude scores between disciplines. Our study successfully recruited a multidisciplinary sample and is the only known study so far to statistically analyse attitudes to dementia between disciplines. No statistical differences between disciplines were found, however this was a relatively small sample size and further study on larger multidisciplinary samples is desirable.

Experience working in the CCL (number of years) did not appear to affect the total Dementia Attitudes Scale score, but there was a statistical difference in the Social Comfort score. Participant age may have played a role in this as the majority (67\%) of those with less than 
five years experience were between the ages of 18-25. Analysis, of the effect of age upon attitude scores did suggest that younger participant had lower Social Comfort scores. However, due to uneven grouping $(<25, n=4 v>26, n=58)$ within our data the meaning of these results cannot be reliably attributed. Further research is needed in this area especially in light of the perception that on-the-job training is most effective, as the longer in role gives a higher opportunity for this kind of education.

This study also considered the impact of personal experience upon attitudes to dementia. Fifty percent of participants had personal experience of a close friend or relative with dementia. No difference was found between participants who have personal experience with those that haven't. A larger sample size would help to fully appreciate the relevance of this finding.

A large amount of the literature reviewing care for patients with dementia discusses the role of training and attitudes to dementia (Duffin, 2013: Chater and Hughes, 2012: Cowdell, 2010: Hunt, 2010: Borbasi et al., 2006). Our study examined possible links between training and attitude scores. Thirty-seven percent $(n=23)$ of our sample had received dementia training and these had statistically higher total Dementia Attitudes Scale and Social Comfort scores when compared to those who hadn't had any training. This suggests that training improves attitudes to dementia. It is difficult from our results to judge whether better attitudes leads to better care as the literature suggests. This would be an interesting area of research to explore.

Participants considered training to be inadequate and agree with the literature in calling for more (Forya, 2013: Baillie et al., 2012: Chater and Hughes, 2012: The Royal College of Psychiatrists, 2011: Cowdell, 2010: Hunt, 2010: Nolan, 2006). We found that $62 \%$ of medical staff had received training, but $86 \%$ of allied professionals had not received training. The UK National Audit of Dementia Care found just 21\% of doctors and $21 \%$ of allied professionals had been provided with dementia training (Royal College of Psychiatrists, pg.59, 2013). These figures are interesting, but it is difficult to draw conclusions due to differences in question wording. Our study asked participants to report 'any' training including training 
received outside of the hospital, whereas the National Audit of Dementia Care (Royal College of Psychiatrists, 2013) examined training provision solely by hospitals.

Unique to this study was the examination of perceived benefit of training methods and resultant effect of training methods upon attitudes to dementia. Results found that although on-the-job training was viewed as the most beneficial format for training, followed by personal experience, neither was found to have a significant effect upon attitude scores.

This study found the CCL recovery area was perceived differently by individuals dependent upon roles performed. This was particularly true of the co-ordinator role carried out in the recovery area and performed predominantly by nurses (63\%). Nurses viewed the recovery area more negatively than consultants and co-ordinators viewed the recovery area less positively than those who did not co-ordinate. Differences in perception of the laboratories, where procedures are performed, between disciplines were less clear. Nurses perceived the laboratories as less appropriate for patients with dementia than consultants or cardiac physiologists and females viewed the recovery area and the laboratories more negatively than males. The role of gender may be an important and interesting area for future research.

When linking these results to the literature the specific challenges of the recovery area could be viewed as similar to acute wards as it is busy, noisy, and unpredictable (Borbasi et al., 2006, Nolan 2006 and McCloskey 2004). Time and task pressure in the recovery area may limit the ability to reassure patients with dementia. Additionally essential equipment and the rotation of staff may not assist in the care of patients with dementia. Our findings resonate with those of Baillie et al., (2012) in that speed, patient throughput and prioritisation of the acutely ill appear more valued than the ability to care appropriately for patients with dementia.

The functional attributes of laboratories made it difficult for the participants to consider how adaptation could occur to improve care of patients with dementia. Safety of all patients must be considered essential and any changes to improve care for patients with dementia will require resources and support from senior staff within the organisation, which some 
participants found was not always forthcoming. A good starting point for an organisation would be to use The Kings Fund's document 'Enhancing the Healing Environment programme' (The Kings Fund, 2013).

This study found the recovery area shared some of the problems faced by wards in relation to organisational demands, noise and unfamiliar faces. However, the direct admission of emergencies and need for functionality was very evident and meant physical care took priority over psychological care. These issues were even more apparent in the laboratories. The difficulty of balancing person-centred care and tasks necessary for procedures in the laboratory was impaired by the presence of equipment and ionising radiation, which frustrated participants attempting to care for patients with dementia holistically. This study found the $\mathrm{CCL}$ environment posed unique challenges for participants that are not found in acute wards and it appears that these issues are complex and influence physical and psychological care of patients with dementia. However, despite these challenges participant comments described the wish and willingness to provide person centred care as much as possible.

\section{Implications and Conclusions}

The number of years' experience had a significant effect upon attitudes to dementia. Our findings suggest that it may be beneficial to provide training on caring for patients with dementia in all professional courses and due to the perception of the participants, it would seem preferable to continue education with short 'on the job' top up training focusing on each area where care is delivered to make it relevant.

It is proposed that to care for patients with dementia appropriately in the Cardiac Catheter Laboratory the environment should be assessed to identify whether there is scope for adaptation. This may require investment in time and resources and given the technological restraints described by participants it may require a different care philosophy and a new way of thinking. 


\section{References}

Alzheimer's Society (2009), Counting the Cost: Caring for people with dementia on hospital wards, London: Alzheimer's Society.

Baillie, L, Merritt, J and Cox, J (2012), "Caring for older people with dementia in hospital. Part one: challenges", Nursing older people, 24(8): 33-37.

Borbasi, S, Jones, J, Lockwood, C and Emden, C (2006), “Health Professionals' Perspectives of Providing Care to People with Dementia in the Acute Setting: Toward Better Practice", Geriatric nursing, 27(5): 300-308.

Chater, K and Hughes, H (2012), "Strategies to deliver dementia training and education in the acute hospital setting", Journal of Research in Nursing, 18(6): 578-593.

Cowdell, F (2010), "The care of older people with dementia in acute hospitals", International Journal of Older People Nursing, 5(2): 83-92.

DOH (2009), Living well with dementia, London: Department of Health Publications.

DOH (2013), Dementia - A state of the nation report on dementia care and support in England, London: Department of Health Publications.

Duffin, C (2013), "Raising awareness to support people with dementia in hospital", Nursing Older People, 25(5): 14-17.

Forya, B (2013), "Push to make dementia training obligatory for all hospital staff", Nursing times, 109(28): 6.

Fukuda, R, Shimizu, Y and Seto, N (2015) Issues experienced while administering care to patients with dementia in acute care hospitals: A study based on focus group interviews. Qualitative Studies on Health and Well-being 10: 25828 http://dx.doi.org/10.3402/qhw.v10.25828

George, J, Long, S and Vincent, C (2013), "How can we keep patients with dementia safe in our acute hospitals? A review of challenges and solutions", Journal of the Royal Society of Medicine, 106(9): 355-361.

GOV.UK (2013), "Improving care for people with dementia", Available at: https://www.gov.uk/government/policies/improving-care-for-people-withdementia (accessed 20 July 2014).

Hunt, N, (2010), "Alzheimer's and the NHS", British journal of nursing, 19(1): 6.

McCloskey, RM (2004), "Caring for patients with dementia in an acute care environment", Geriatric nursing, 25(3): 139-144. 
Nightingale S, Holmes JD, Mason J, House AO. (2001) Psychiatric illness and mortality after hip fracture. The Lancet. 357 (9264):1264-1265

Nilsson, A, Lindkvist, M, Rasmussen, BH and Edvardsson, D (2012), "Staff attitudes towards older patients with cognitive impairment: need for improvements in acute care", Journal of nursing management, 20(5): 640-647.

Nolan, L (2006), “Caring connections with older persons with dementia in an acute hospital setting-a hermeneutic interpretation of the staff nurse's experience", International Journal of Older People Nursing, 1(4): 208-215.

O'Connor, ML and McFadden, SH (2010), "Development and psychometric validation of the dementia attitudes scale",

Available at: http://www.hindawi.com/journals/ijad/2010/454218/abs/ (accessed 27

October 2013).

Royal College of Psychiatrists, (2011), "Report of the national audit of dementia care in general hospitals. Healthcare Improvement Quality Partnership", Available at: http://www.cpa.org.uk/cpa/docs/RoyalCollegeofPsychiatristsReportoftheNationalAuditofDementiaCareinGeneralHospitals2011.pdf (accessed 28 June 2014).

Royal College of Psychiatrists, (2013), "National Audit of Dementia Care in general hospitals 2012-13. Second round Audit Report and Update. Healthcare Improvement Quality Partnership",

Available at:

http://www.rcpsych.ac.uk/pdf/NAD\%20NATIONAL\%20REPORT\%202013\%20reports\%20pag e.pdf (accessed 28 June 2014).

Spencer, K, Foster, P, Whittamore, KH, Goldberg, SE and Harwood, RH (2013) Delivering dementia care differently - evaluating the differences and similarities between a specialist medical and mental health unit and standard acute care wards: a qualitative study of family carers' perceptions of quality of care. BMJ Open 3:e004198. doi: 10.1136/bmjopen-2013004198

The Kings Fund (2013), "Is your ward dementia friendly?"

Available at: http://www.kingsfund.org.uk/sites/files/kf/EHE-dementia-assessment-tool.pdf (accessed 6 July 2014).

Walker, J and Almond, P (2010). Interpreting Statistical Findings: A guide for health professionals and students. Maidenhead: Open University Press.

World Health Organisation (2012a), "Dementia: fact sheet No. 362", Available at: http://www.who.int/mediacentre/factsheets/fs362/en/ (accessed 13 July 2104). 
World Health Organisation (2012b), Dementia: A public health challenge, United Kingdom: World Health Organisation. 


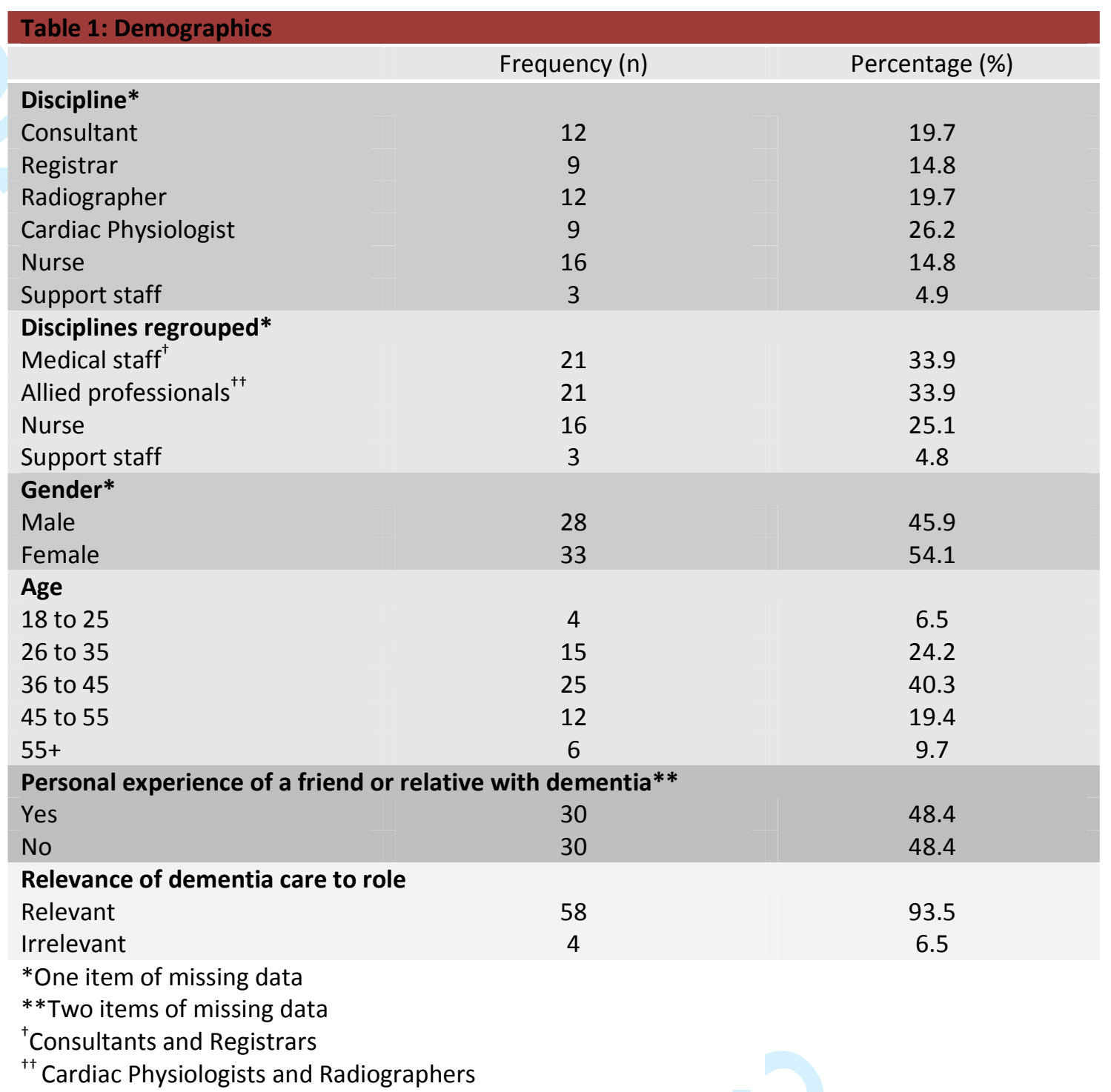


Training received per discipline

\section{Table 2: Training received frequencies}

Consultant

Registrar

Nurse

Cardiac Physiologist

Radiographer

Support staff

Training received per regrouped disciplines

Medical Staff ${ }^{\dagger}$

13

Allied professionals ${ }^{\dagger+}$

Nurses

3

Support staff

5

${ }^{\dagger}$ Consultants and Registrars

${ }^{+\dagger}$ Cardiac Physiologists and Radiographers

\section{Table 3: Perception of the patient with dementia journey and care delivered in the Cardiac} Catheter Laboratories.

\begin{tabular}{|c|c|c|c|c|}
\hline & \multicolumn{2}{|c|}{ Perception of patient journey } & \multicolumn{2}{|c|}{ Perception of care delivered } \\
\hline & $\begin{array}{c}\text { Frequency } \\
\text { (n) }\end{array}$ & Percentage (\%) & $\begin{array}{c}\text { Frequency } \\
\text { (n) }\end{array}$ & Percentage (\%) \\
\hline Missing data & 2 & - & 1 & - \\
\hline 1=Poor & 3 & 5.0 & 3 & 4.9 \\
\hline 2 & 30 & 50.0 & 10 & 16.4 \\
\hline 3 & 27 & 45.0 & 40 & 65.6 \\
\hline 4=Excellent & 0 & 0 & 8 & 13.1 \\
\hline Total $\mathbf{n}$ & 62 & - & 62 & - \\
\hline
\end{tabular}

